SHORT REPORT

\title{
Psychological characteristics of patients with newly developed psychogenic seizures
}

\author{
T van Merode, M Twellaar, I A W Kotsopoulos, A G H Kessels, H Merckelbach, \\ M C T F M de Krom, J A Knottnerus
}

J Neurol Neurosurg Psychiatry 2004;75:1175-1 177. doi: 10.1136/jnnp.2003.016923

\begin{abstract}
Objectives: To assess psychopathological symptoms and history of childhood trauma in patients with newly developed psychogenic seizures.

Methods: Using validated scales, 178 patients from the general population diagnosed with newly developed seizures were assessed, at a point in time when the nature of their seizures was yet unknown to either doctors or patients. After standardised neurological examination, 138 patients were diagnosed with non-psychogenic seizures (NPS), while 40 patients were found to have psychogenic seizures (PS). To evaluate possible differences between the genders and the diagnostic groups, univariate analyses of variance were done.

Results: PS patients reported significantly more comorbid psychopathological complaints, dissociative experiences, anxiety, and self-reported childhood trauma than NPS patients. In addition, PS patients had lower quality of life ratings than NPS patients. These effects were not modulated by gender.

Conclusions: The results of the present study indicate that patients with newly developed PS constitute a group with complex psychopathological features that warrant early detection and treatment.
\end{abstract}

$\mathrm{T}$ he aetiology of non-epileptic non-organic seizures, also referred to as psychogenic seizures, non-epileptic attack disorder or pseudoseizures, is largely unknown. ${ }^{12}$ In particular, there are no studies addressing the psychological features of new incident cases.

Patients with non-epileptic non-organic seizures (hereafter called psychogenic seizures), usually are first seen and treated by neurologists. Then, as the nature of the seizure becomes obvious, these patients are generally referred to psychiatric care facilities. Nearly all studies on the psychological features of patients with psychogenic seizures rely on prevalent cases. The problem with this approach is that patients have extensive experience with their seizures, may come from selected populations resulting in selection and case severity bias, and/or may have been or still are on antiepileptic or other medication. Thus, precisely because of their seizures, new psychogenic comorbidity may obscure the original antecedents and correlates. Although studies on prevalent cases have yielded valuable information, such studies do not provide unbiased insight into the early psychological characteristics of psychogenic seizures.

Systematic comparisons between patients with recent onset psychogenic seizures and patients with recent onset of non-psychogenic seizures may lead to a better understanding of psychological concomitants and, perhaps, the aetiology of psychogenic seizures. Assessment of coping styles, ${ }^{3}$ comorbid psychopathology, ${ }^{4}$ and self-reported childhood abuse, ${ }^{67}$ especially when prospectively conducted at first presentation of the seizures, may well inform treatment strategies.

In the present study we assessed the psychological characteristics of patients with psychogenic seizures and non-psychogenic seizures at the time of first presentation at the hospital-that is, when the final diagnosis had not yet been made.

\section{METHODS \\ Patients}

The study was conducted as part of a prospective population based research project, ${ }^{8}$ that covered a well circumscribed area in the southern part of the Netherlands with approximately 190000 inhabitants, served by a single hospital. Included were all newly presenting patients aged more than 14 years suspected of having had a first seizure. Patients were identified over a two year period (from October 1998 to October 2000) by medical practitioners in the General Practice and Emergency Room who were given information and instructions about the inclusion criteria. Patients with acute symptomatic seizures were excluded from the study. Identified patients were evaluated and neurologically examined in a standardised manner. Two neurologists independently evaluated all cases and classified a patient's seizure as a non-psychogenic seizure (NPS; epileptic seizure or nonepileptic seizure of organic origin) or a psychogenic seizure (PS; non-epileptic seizure of non-organic origin). Their definitive classification, six months after the index seizure, was based on clinical manifestations, electroencephalogram findings, neuroimaging, laboratory, and electrocardiogram data. In case of disagreement, consensus was reached with the help of a third neurologist. Interrater agreement $(\kappa)$ was 0.93 .

\section{Measurements}

At the time of the standardised evaluation (usually only a couple of days after their first seizure), when the diagnosis was still unknown, each patient was administered (double blind, usually within days after the index seizure) the following well-validated questionnaires and scales:

- Symptom Check List (SCL-90), which is a multi-dimensional index of psychopathology ${ }^{9}$

Abbreviations: $C T Q$, Childhood Trauma Questionnaire; DES, Dissociative Experience Scale; NPS, Non-psychogenic seizures; PS, psychogenic seizures; QOLIE, Quality of Life in Epilepsy Inventory; SAMT, Semantic Autobiographical Memory Test; SAS, Self-rating Anxiety Scale; SCL, Symptom Check List; STAI, State-Trait Anxiety Inventory; UCL, Utrecht Coping List 
- Childhood Trauma Questionnaire (CTQ), a 70 item selfreport inventory that screens for maltreatment experiences before the age of 18 years ${ }^{10}$

- Dissociative Experience Scale (DES), a 28 item self-report instrument measuring the frequency of dissociative symptoms ${ }^{11}$

- Self-rating Anxiety Scale (SAS), a 20 item questionnaire ${ }^{12}$

- State-Trait Anxiety Inventory (STAI), a self-report measure of subjective anxiety ${ }^{13}$

- 31 item Quality of Life in Epilepsy Inventory (QOLIE-31) which assesses health related quality of life ${ }^{14}$

- Utrecht Coping List (UCL), which is a 47 item Dutch questionnaire measuring coping behavior (ACT: active coping behavior; PAS: passive coping behavior $)^{15}$

- Semantic Autobiographical Memory Test (SAMT), a Dutch questionnaire asking for "personal facts" or self-referent semantic knowledge. ${ }^{16}$

The SCL, CTQ, DES, SAS and STAI were all in the format of validated Dutch translations.

\section{Data analysis}

The final sample consisted of 178 patients $(79 \%)$ from a total of 226 and these patients completed all questionnaires. Of 178, 138 patients were diagnosed with NPS (93 epileptic and 45 non-epileptic organic) and 40 patients with PS. Results of the questionnaires were incorporated into the database by the second author, who was blinded and unaware of the diagnosis at that time.

The scores of the NPS and PS groups were subjected to $2 \times 2$ ( (groups: NPS $v$ PS $) \times($ men $v$ women $))$ analyses of variance (ANOVA) with age as a covariate. The significance level was set at 0.05 .

\section{RESULTS}

Table 1 summarises the results of the ANOVA.

The mean age of the PS group $(35 \pm 18$ years) was significantly lower than that of the NPS group $(49 \pm 19$ years; $\mathrm{p}<0.001$ ) The percentage of women was not significantly higher $(\mathrm{p}=0.11)$ in the PS group compared with the NPS group (65\% and 50\%, respectively).

The ANOVA carried out on the questionnaire data revealed no significant effect of sex, nor were there any interaction effects. Age proved to be a significant covariate for CTQ in that higher rates of self-reported childhood trauma were found in older patients.

The PS group scored significantly higher on SCL, CTQ, DES, SAS, STAI-state and STAI-trait. Also the quality of life ratings of the PS group were significantly lower than those of the NPS group. The two groups did not differ with regard to UCL and SAMT.

Table 1 Results of the univariate analysis of variance

\begin{tabular}{lllll}
\hline \multicolumn{5}{c}{ Significance of main effects } \\
\cline { 2 - 5 } & Sex & Group (NPS/PS) & Interaction & Age \\
\hline SCL & 0.10 & $0.00^{*}$ & 0.87 & 0.95 \\
CTQ & 0.98 & $0.03^{*}$ & 0.97 & $0.00^{*}$ \\
DES & 0.79 & $0.04^{*}$ & 0.49 & 0.77 \\
SAS & 0.05 & $0.00^{*}$ & 0.58 & 0.71 \\
STAl-state & 0.14 & $0.01^{*}$ & 0.25 & 0.18 \\
STAI-trait & 0.12 & $0.03^{*}$ & 0.10 & 0.46 \\
QOL & 0.29 & $0.00^{*}$ & 0.27 & 0.45 \\
UCL-ACT & 0.26 & 0.25 & 0.75 & 0.73 \\
UCL-PAS & 0.40 & 0.52 & 0.34 & 0.05 \\
SAMT & 0.51 & 0.45 & 0.76 & 0.75 \\
\hline * $<<0.05$. & \multicolumn{5}{c}{} \\
For abbreviations see text. & &
\end{tabular}

\section{DISCUSSION}

In the current study, the proportion of women in the PS group $(65 \%)$ was not substantially higher than that in the NPS group $(50 \%)$. This is at odds with previous studies, in which percentages of women in psychogenic seizure samples were as high as $75-83 \%{ }^{17}{ }^{18}$ A crucial difference between our study and previous work is that our study relied on a prospective approach aiming at incident cases in the general population. Therefore it lacks the shortcomings of prevalent studies like severity bias and selection bias.

On a similar note, for both PS and NPS patients, we failed to find gender-related differences in the questionnaire scores. Again, this may be surprising, as some authors have argued that in general, women display more psychopathological symptoms than men. ${ }^{19}{ }^{20}$ Some authors seem to assume that this explains the alleged overrepresentation of women among patients with $\mathrm{PS},{ }^{17}$ and some have suspected a causal link between gender-linked psychopathology and psychological seizures. ${ }^{12}$ Our results do not support this view.

Like gender, age did not contribute to the questionnaire scores of PS and NPS patients. There was one notable exception: older patients reported more childhood abuse on the CTQ than younger patients. We suspect that aversive childhood experiences during World War II as well as the lack of societal sensitivity to issues related to child abuse in years before the 1980s account for the higher levels of selfreported childhood abuse in our older patients. Although gender and age did little to explain differences between PS and NPS patients, a straightforward pattern emerged in the present study. That is, PS patients reported more psychopathological complaints on the SCL-90, more dissociative symptoms (as indexed by the DES), and more state and trait anxiety (as measured by SAS and STAI). That PS patients suffer from comorbid psychopathology is a recurrent theme in the literature. ${ }^{4122}$ However, our study extends earlier work by showing that the range of concomitant psychopathology in PS patients is surprisingly broad (ranging from anxiety and depression to dissociation). Moreover, our study clearly demonstrates that comorbid psychopathology is typical for new cases of PS, indicating that it is not persistent PS that produces psychopathology.

Interestingly, PS patients not only reported high anxiety levels, but also displayed heightened trait-that is, chronic anxiety. Thus, the simple view that their reported anxiety is a result of seizures is unlikely to be true. Perhaps, then, high anxiety levels are a core characteristic of persons prone to develop PS. In line with this, patients with PS reported a lower health related quality of life, even when compared with patients with organic based seizures.

Our results do not support the idea ${ }^{32}$ that passive coping styles and/or difficulties recalling specific autobiographical memories are typical for patients with PS. However, PS patients did report more physical neglect and sexual abuse than NPS patients. The link between sexual abuse and PS is well recognized ${ }^{5-7}$ in the literature, as is the combination of physical neglect/abuse and sexual abuse. ${ }^{1821}$ Thus, our findings are well in line with those of a recent small scale study that also found trauma related psychopathology to be typical for patients with PS. ${ }^{24}$ Taken together, the evidence suggests that a history of childhood abuse might be involved in the aetiology of at least some cases of PS. Such an interpretation would also nicely fit with the raised anxiety scores and the lowered quality of life ratings of PS patients.

On the other hand, the self-report measures used in the current study are sensitive to all sorts of biases and combined with a cross-sectional methodology, this precludes firm conclusions about precise causal links. ${ }^{25}$ What can be said with some confidence, though, is that patients with newly developed PS report a broad range of psychopathological 
complaints, along with reports of aversive childhood experiences and poor quality of life. Clearly, this issue warrants prospective longitudinal studies. Such studies are important given that early differential diagnosis of true epileptic versus psychogenic fits is notoriously difficult. Better diagnostic tools are urgently needed in this domain, as are early treatment interventions for those who suffer from PS.

\section{Authors' affiliations}

T van Merode, M Twellaar, J A Knottnerus, Department of General Practice, Maastricht University, Maastricht, the Netherlands I A W Kotsopoulos, M C T F M de Krom, Department of Neurology, Maastricht University Hospital, Maastricht, the Netherlands A G H Kessels, Department of Clinical Epidemiology and Medical Technology Assessment, Maastricht University Hospital, Maastricht, the Netherlands

H Merckelbach, Department of Psychology, Maastricht University, Maastricht, the Netherlands

Competing interests: none declared

Correspondence to: T van Merode, Maastricht University, Department of General Practice/Women and Health, PO Box 616, 6200 MD Maastricht, the Netherlands; Tiny.vanMerode@

hag.unimaas.nl

Received 15 April 2003

In revised form 4 November 2003

Accepted 14 November 2003

\section{REFERENCES}

1 Krumholz A. Nonepileptic seizures: diagnosis and management. Neurology 1999;53(suppl 2):S76-S83.

2 Francis $\mathbf{P}$, Baker GA. Non-epileptic attack disorder (NEAD): a comprehensive review. Seizure 1999;8:53-61.

3 Goldstein LH, Drew C, Mellers J, et al. Dissociation, hypnotizability, coping styles and health locus of control: characteristics of pseudoseizure patients. Seizure 2000;9:314-22.
4 Ramchandani D, Schindler B. Evaluation of pseudoseizures. A psychiatric perspective. Psychosomatics 1993;34:70-9.

5 Bowman ES. Etiology and clinical course of pseudoseizures. Relationship to trauma, depression, and dissociation. Psychosomatics 1993;34:333-42.

6 Goodwin J, Simms M, Bergman R. Hysterical seizures: a sequel to incest. Am J Orthopsychiatry 1979;49:698-703.

7 Griffith JL, Polles A, Griffith ME. Pseudoseizures, families, and unspeakable dilemmas. Psychosomatics 1998;39:144-53.

8 Kotsopoulos IAW. Seizures: incidence, diagnostic aspects and the costs of epilepsy [Thesis]. Maastricht University, Maastricht, 2002.

9 Arrindell WA, Ettema JHM. SCL-90: Handleiding bij een multidimensionele psychopathologie-indicator. Lisse: Swets en Zietlinger BV, 1986.

10 Bernstein DP, Fink L. Manual for the childhood trauma questionnaire (CTQ). Bronx, NY: Veterans Affairs Medical Center, 1994.

11 Bernstein EM, Putnam FW. Development, reliability, and validity of a dissociation scale. J Nerv Ment Dis 1986;174:727-35

12 Zung WWK. A rating instrument for anxiety disorders. Psychosomatics $1971 ; 12: 371-9$.

13 Spielberger CD, Gorsuch RL, Lushene R, et al. Manual for the State-Trait Anxiety Inventory. Palo Alto, CA: Consulting Psychologists Press, 1983.

14 Cramer JA, Perrine K, Devinsky O, et al. Development and cross-cultural translation of a 31 -item quality of life in epilepsy inventory. Epilepsia 1998;39:81-8.

15 Schreurs PJG, van de Willige G, Bosschot JF, et al. Utrecht Coping List: Handbook. Lisse: Swets \& Zeitlinger, 1988.

16 Meesters C, Merckelbach H, Muris P, et al. Autobiographical memory and trauma in adolescents. J Behav Ther Exp Psychiatry 2000;31:29-39.

17 Shen W, Bowman ES, Markand ON. Presenting the diagnosis of pseudoseizure. Neurology 1990:40:756-9.

18 Betts T, Boden S. Diagnosis, management and prognosis of a group of 128 patients with non-epileptic attack disorder. Part II. Previous childhood sexual abuse in the aetiology of these disorders. Seizure 1992;1:27-32.

19 Freud S. The etiology of hysteria. London: Hogarth, 1968.

20 Olkinuora M. Psychogenic epidemics and work. Scand J Work Environ Health 1984; 10(Spec No):501-4.

21 Bowman ES, Markand ON. Psychodynamics and psychiatric diagnoses of pseudoseizure subjects. Am J Psychiatry 1996;153:57-63.

22 Blumer $\mathbf{D}$. The paroxysmal somatoform disorder: a series of patients with nonepileptic seizures. In: Rowan AJ, Gates JR, eds. Non-epileptic seizures. Boston: Butterworth-Heinemann, 1993:165-72.

23 Frances PL, Baker GA, Appleton PL. Stress and avoidance in pseudoseizures: testing the assumptions. Epilepsy Res 1999:34:241-9.

24 Fleisher W, Staley D, Krawetz P, et al. Comparative study of trauma-related phenomena in subjects with pseudoseizures and subjects with epilepsy. Am J Psychiatry 2002;159:660-3.

25 Merckelbach H, Muris P. The causal link between self-reported trauma and dissociation: a critical review. Behav Res Ther 2001;39:245-54. 